\title{
sciendo
}

\section{THE FIRST INSIGHTS ON TRANS-GALACTOOLIGOSACCHARIDE EFFECTS ON FATTY ACIDS PROFILE AND MICROSTRUCTURE OF MUSCLE IN COMMON CARP*}

\author{
Ewa Ziółkowska ${ }^{`}$, Joanna Bogucka ${ }^{1}$, Mateusz Rawski², Jan Mazurkiewicz², Giuseppe Maiorano ${ }^{3}$, \\ Magdalena Stanek ${ }^{1}$
}

\author{
${ }^{1}$ Department of Animal Physiology, Physiotherapy and Nutrition, Faculty of Animal Breeding \\ and Biology, Bydgoszcz University of Science and Technology, Mazowiecka 28, 85-004 Bydgoszcz, \\ Poland \\ ${ }^{2}$ Division of Inland Fisheries and Aquaculture, Faculty of Veterinary Medicine and Animal Science, \\ Poznań University of Life Sciences, Wojska Polskiego 71C, 60-625 Poznań, Poland \\ ${ }^{3}$ Department of Agricultural, Environmental and Food Sciences, University of Molise, \\ Via F. De Sanctis snc, 86100 Campobasso, Italy \\ •Corresponding author: ewa.ziolkowska@pbs.edu.pl
}

\begin{abstract}
The aim of the study was to determine the effects of prebiotic GOS on muscle histomorphometry and the total lipid, total cholesterol content and fatty acids profile in the meat of common carp. The 60-day-long experiment was performed on one-year-old fish. Three diets were used in the experiment: control diet 1 (C) with no microbiota affecting feed additives, diet 2 (B1) with $1 \%$ of GOS, and diet 3 (B2) with $2 \%$ of GOS. At the end of the trial, 16 individuals from each treatment group were used for the analyses. Fish meat from the B1 group had significantly higher lipid content compared to B2, but neither B1 nor B2 groups were different from the control group. The percentages of SFA, MUFA, PUFA, indexes n-3/n-6, PUFA/SFA, AI and TI, and total cholesterol content

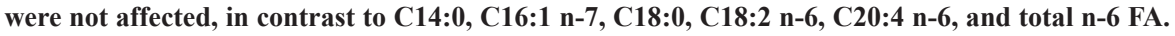
GOS significantly increased the percentage of normal fibres, while the lower amount of fibre atrophy and splitting was observed. The results confirm that diet supplemented with $2 \%$ GOS may be recommended as feed additive in carp nutrition due to positive effects on some fatty acids profiles and muscle microstructure.
\end{abstract}

Key words: cholesterol, fatty acids, meat quality, prebiotics, fish

To meet the growing demand for foods of animal origin, it is necessary to increase the efficiency of animal farming. One of the basic sectors of agriculture that

*This work has been supported by the Polish National Agency for Academic Exchange under Grant No. PPI/APM/2019/1/00003. Research conducted with the statutory funding No. 506.511.04.00 of the Faculty of Veterinary Medicine and Animal Science, Poznań University of Life Sciences, Poland; Division of Inland Fisheries and Aquaculture. 
has been developing rapidly over the past few years is fish farming (Godfray et al., 2010; Kurdomanov et al., 2019). However, it is necessary to reduce production costs by improving disease resistance and therefore improving survival, feed efficiency, and the growth performance of farmed fish species. To modulate the intestinal microflora, feed additives and supplements such as probiotics and prebiotics are used. Prebiotics are fermented by beneficial bacteria such as Lactobacillus and Bifidobacterium, and can alter the composition of organisms in the gut microbiome, leading to a decrease in the growth of potentially pathogenic microbes living in the gastrointestinal tract and to an increase in the number of health-beneficial microbiota (Guerreiro et al., 2015; Grisdale-Helland et al., 2008; Macfarlane et al., 2006; Talpur et al., 2014). Prebiotics as non-digestible feed additives have the ability to bind water in the intestinal lumen, increasing the volume of the intestinal contents, making them a very good fermentation substrate for probiotics (Mazurkiewicz et al., 2008). All currently accepted prebiotics are carbohydrates, polyphenols and polyunsaturated fatty acids (Gibson et al., 2017; Lockyer and Stanner, 2019).

Moreover, prebiotics were used as feed additives to improve the efficiency of cyprinids production, growth performance, gut microbiota and the activity of digestive enzymes (Markowiak and Śliżewska, 2018; Cao et al., 2019; Dawood and Koshio, 2016; Ebrahimi et al., 2012; Hoffmann et al., 2017; Hoseinifar et al., 2016; Mousavi et al., 2016; Guerreiro et al., 2017 a; Wang et al., 2020). The addition of prebiotics to feed may improve nutrient metabolism and meat quality, as evidenced by an increase in the percentage of protein, fat, minerals and carbohydrates (Cao et al., 2019; Puchała and Pilarczyk, 2007; Sun et al., 2017; Hussein et al., 2016; Scholz-Ahrens et al., 2007). Several studies indicated that prebiotics, such as fructooligosaccharides (FOS), xylooligosaccharides (XOS), galactooligosaccharides (GOS), and immunogen can affect haematological and serum biochemical parameters (Ebrahimi et al., 2012; Mousavi et al., 2016; Akhter et al., 2015; Ziółkowska et al., 2020). Despite the potential benefits of prebiotics to performance, as noted in a wide variety of animal species, information pertaining to their application in aquaculture is abundant, but it is extremely limited with respect to their influence on lipid composition and fatty acids profile.

Lipids are deposited in adipose tissue and, in smaller amounts, in the liver and muscles. Intramuscular fat (IMF) content has a beneficial effect on the taste, juiciness and firmness of fish meat (Hocquette et al., 2010). An appropriate type of fatty acid may contribute to preventing the development of coronary diseases, which is why fish consumption in the world is systematically increasing (Levitan et al., 2010; Schmidt et al., 2005; Leaf et al., 2003; Guillen et al., 2019). Many studies carried out over the years have shown that prebiotics may contribute to increased fish weight gain (Guerreiro et al., 2015; Kurdomanov et al., 2019; Mazurkiewicz et al., 2008). However, faster weight gain can result in the destruction of muscle fibre. A consequence of this may be the appearance of histopathological changes in the muscle (Bogucka et al., 2018).

The prebiotic used in the experiment was trans-galactooligosaccharide, GOS (trade name: $\mathrm{Bi}^{2}$ tos, Clasado Biosciences Ltd., Jersey, UK). It is manufactured by enzymatic transgalactosylation of the milk lactose by the whole cells of Bifidobac- 
terium bifidum 41171 and specifically promotes growth of Bifidobacterium spp. (Tzortzis et al., 2005). The genome of Bifidobacterium spp. encodes carbohydratedegrading enzymes with a high affinity to GOS (Pokusaeva et al., 2011). In fermentation experiments carried out by Tzortzis et al. (2005) B. bifidum showed an increased preference towards the produced galactooligosaccharide mixture, displaying a higher growth rate and short-chain fatty acid production when compared with commercially available oligosaccharides. Bifidobacterium, a member of the Actinobacteria group, is present in fish gut and plays an important role in inflammation of the intestine (Banerjee and Ray, 2017; Wang et al., 2020).

The aim of the present study was to analyse the effects of dietary supplementation with $1 \%$ and $2 \%$ trans-galactooligosaccharide (GOS) on lipid composition and muscle microstructure of common carp. Carp is an important economic fish cultured in Poland, and our country is the largest carp producer in the European Union (FAO, 2020). The research conducted by Hoseinifar et al. (2016) revealed that different prebiotics modulate carp growth and immune response differently, and GOS seems to be the most suitable prebiotic.

\section{Material and methods}

Studies on live animals were carried out in strict accordance with the recommendations of the National Ethics Commission (Warsaw, Poland). All members of the research staff were trained in animal care, handling, and euthanasia. Fish health and welfare and the environmental conditions in the experimental tanks were checked twice daily by visual observation of animal behaviour and by checking water quality parameters such as oxygen saturation, temperature, and water flow.

\section{Fish culture and experimental diets}

The 60-day growth trial was carried out at the Experimental Station for Feed Production Technology and Aquaculture in Muchocin (Poland). Three hundred oneyear-old common carp (mean body weight $180 \mathrm{~g}$ ) were used. The fish were randomly stocked into 12 concrete ponds $\left(40 \mathrm{~m}^{3}\right)$ at a density of 25 fish per pond in accordance with Horváth et al. (2002). The experiment was carried out in four replications (four ponds per treatment). Each pond was equipped with an automatic band feeder allowing for the continuous supply of feed throughout a daily 12 -hour period. The calculated daily feed dose for each pond was given every day at 9:00 a.m.; its consumption was controlled visually twice a day, with the rate corrected if needed. The daily feed dose was restricted to assure that all feed supplied was consumed. The feeding rate was calculated in consideration of the fish biomass in each pond, which was corrected every 10 days on the basis of control by the bulk weighing of all fish; measurements of the current average daily water temperature and prior-day feed consumption were used for additional correction according to Miyatake's (1997) recommendations, which resulted in a feeding rate ranging from 1.8 to $3.3 \%$ of the fish biomass. A constant flow of water in the experimental system was ensured by an 
open-flow system with a mechanical pre-filtration chamber. During the experimental period, control of water physio-chemical parameters was carried out with the use of microcomputer oxymeter Elmetron CO-315. Measurements were taken of the average daily water temperature and $\mathrm{pH}$, which ranged from $17.7^{\circ} \mathrm{C}$ to $22.7^{\circ} \mathrm{C}$ and 7.2

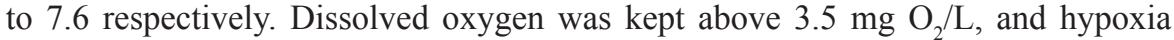
conditions were not observed in the experiment (details are described in Ziółkowska et al., 2020).

The experimental diets were calculated as isonitrogenous (35.1\% crude protein) and isoenergetic (18.5 $\mathrm{MJ} \mathrm{kg}^{-1}$ ) with less than $4 \%$ of crude fibre and were formulated according to common carp nutritional requirements (NRC, 2011; De Silva and Anderson, 1995; Takeuchi et al., 2002). The extrusion conditions used to prepare the feed were described in detail by Ziółkowska et al. (2020). Three experimental diets were used: control diet 1 (C) without feed additives, diet 2 with $1 \%$ of GOS (B1) and diet 3 (B2) with $2 \%$ of GOS (Table 1). Details of feed intake, utilisation, and growth parameters are given in Ziółkowska et al. (2020).

Table 1. Dietary formulation and proximate composition of feed

\begin{tabular}{|c|c|c|c|}
\hline \multirow{2}{*}{ Ingredient } & \multicolumn{3}{|c|}{ Composition (\%) } \\
\hline & $\mathrm{C}$ & B1 & B2 \\
\hline 1 & 2 & 3 & 4 \\
\hline Fish meal $^{1}$ & 12.3 & 12.3 & 12.3 \\
\hline Blood meal $^{2}$ & 10.0 & 10.0 & 10.0 \\
\hline DDGS $^{3}$ & 11.0 & 11.0 & 11.0 \\
\hline Soybean meal ${ }^{4}$ & 15.0 & 15.0 & 15.0 \\
\hline Rapeseed meal ${ }^{5}$ & 10.0 & 10.0 & 10.0 \\
\hline Wheat meal & 32.8 & 31.8 & 30.8 \\
\hline Fish oil ${ }^{6}$ & 4.6 & 4.6 & 4.6 \\
\hline Soybean lecithin ${ }^{7}$ & 1.0 & 1.0 & 1.0 \\
\hline Vitamin-mineral premix ${ }^{8}$ & 1.5 & 1.5 & 1.5 \\
\hline Vitamin premix ${ }^{9}$ & 0.1 & 0.1 & 0.1 \\
\hline Choline chloride & 0.2 & 0.2 & 0.2 \\
\hline Fodder chalk & 1.5 & 1.5 & 1.5 \\
\hline Prebiotic $^{10}$ & 0.0 & 1.0 & 2.0 \\
\hline \multicolumn{4}{|c|}{ Proximate composition (\% dry matter) } \\
\hline Crude protein & & 35.06 & \\
\hline Crude lipid & & 9.08 & \\
\hline Crude fibre & & 3.93 & \\
\hline Total phosphorus & & 0.83 & \\
\hline Calcium & & 1.36 & \\
\hline Ash & & 7.17 & \\
\hline
\end{tabular}


Table 1 - contd.

\begin{tabular}{|c|c|c|c|}
\hline 1 & 2 & 3 & 4 \\
\hline Gross energy $\left(\mathrm{MJ} \cdot \mathrm{kg}^{-1}\right)$ & & 18.51 & \\
\hline Essential amino acids & & ( $\mathrm{g} / 100 \mathrm{~g}$ of crude protein) & \\
\hline Arginine & & 4.53 & \\
\hline Histidine & & 2.8 & \\
\hline Lysine & & 3.5 & \\
\hline Tryptophan & & 1.04 & \\
\hline Phenylalanine + Tyrosine & & 4.96 & \\
\hline Methionine + Cysteine & & 1.75 & \\
\hline Threonine & & 3.13 & \\
\hline Leucine & & 6.72 & \\
\hline Isoleucine & & 3.9 & \\
\hline Valine & & 4.97 & \\
\hline
\end{tabular}

${ }^{1}$ Danish fishmeal, Type F, $72 \%$ total protein, $12 \%$ fat, FF Skagen, Denmark.

${ }^{2}$ AP 301 P, 92\% total protein, APC (GB) Ltd, Ings Road, Doncaster, UK.

${ }^{3}$ Stillage $>45 \%$ total protein, $<6 \%$ ash.

${ }^{4}$ Toasted, $46-47 \%$ total protein.

$533 \%$ total protein, $2 \%$ fat.

${ }^{6}$ Agro-fish, Kartoszyno, Poland.

${ }^{7}$ BergaPure, deoiled lecithin, 97\% pure lecithin, Berg + Schmidt GmbH \& Co. KG, Hamburg, Germany. ${ }^{8}$ Polfamix W, BASF Polska Ltd. Kutno, Poland - 1 kg contains: vitamin A 1000000 IU, vitamin $\mathrm{D}_{3} 200000$ IU, vitamin E $1.5 \mathrm{~g}$, vitamin K $0.2 \mathrm{~g}$, vitamin $\mathrm{B}_{1} 0.05 \mathrm{~g}$, vitamin $\mathrm{B}_{2} 0.4 \mathrm{~g}$, vitamin $\mathrm{B}_{12} 0.001 \mathrm{~g}$, nicotinic acid $2.5 \mathrm{~g}$, D-calcium pantothenate $1.0 \mathrm{~g}$, choline chloride $7.5 \mathrm{~g}$, folic acid $0.1 \mathrm{~g}$, methionine $150.0 \mathrm{~g}$, lysine $150.0 \mathrm{~g}, \mathrm{Fe} 2.5$ g, Mn 6.5 g, Cu 0.8 g, Co 0.04 g, Zn 4.0 g, I 0.008 g, carrier up to 1000.0 g.

${ }^{9}$ Vitazol AD $\mathrm{AD}_{3}$, BIOWET Drwalew, Poland - 1 kg contains: vitamin A 50000 IU, vitamin $\mathrm{D}_{3} 5000$ IU, vitamin E $30.0 \mathrm{mg}$, vitamin C $100.0 \mathrm{mg}$.

${ }^{10} \mathrm{Bi}^{2} \operatorname{tos}^{\circledR}$ trans-galactooligosaccharide (GOS), Clasado Ltd.

During the experiment the fish were anesthetised by immersion in $130 \mathrm{mgL}^{-1}$ tricaine methanesulfonate (MS-222, Sigma Aldrich) for weighing at 10-day intervals for feed rate control. Body weight gain (BWG), feed intake (FI), feed conversion ratio (FCR), specific growth rate (SGR), protein efficiency ratio (PER) and percentage weight gain (PWG) were calculated (details are described in Ziółkowska et al., 2020). At the end of the experiment four fish per pond were euthanised by immersion in $500 \mathrm{mg} \mathrm{L}^{-1}$ of MS-222 (Topic Popovic et al., 2012) for tissue sampling for chemical and histomorphological analysis. After sedation, the animals were decapitated according to the American Veterinary Medical Association Guidelines for the Euthanasia of Animals (Leary et al., 2013). In accordance with Polish law and an EU directive (no 2010/63/EU), the experiments conducted in this study did not require approval from the Local Ethical Committee for Experiments on Animals in Poznań. The number of individuals subjected to analyses was based on earlier studies performed by Hoffmann et al. (2020) and Józefiak et al. (2019) to provide a necessary sample size for laboratory and statistical analysis, and to avoid unnecessary animal sacrifice (according to 4R policy). 


\section{Nutritional composition}

The fillet samples ( $n=16 /$ treatment) were taken for analyses from the large side muscle of fish body above the lateral line (Musculus rectus dorsalis). Fillets were transported on dry ice at $-78^{\circ} \mathrm{C}$ and then stored at $-20^{\circ} \mathrm{C}$ until analysed. Nutritional analyses were conducted at University of Molise (Italy).

\section{Total cholesterol determination}

Total cholesterol $(\mathrm{TCH})$ was extracted from the meat samples using the method of Maraschiello et al. (1996) and then quantified using HPLC system. A Kontron HPLC (Kontron Instruments, Milan, Italy) model 535, equipped with a Kinetex $5 \mu$ C18 reverse-phase column $(150 \times 4.6 \mathrm{~mm} \times 5 \mu \mathrm{m}$; Phenomenex, Torrance, CA $)$, was used. The HPLC mobile phase consisted of acetonitrile and 2-propanol (55:45, vol/ vol) at a flow rate of $1.0 \mathrm{~mL} / \mathrm{min}$. The detection wavelength was $210 \mathrm{~nm}$. The quantitation of muscle cholesterol content was based on the external standard method using a pure cholesterol standard (Sigma, St. Louis, MO).

\section{Total lipid and fatty acid composition}

Total lipids (TL) were extracted following the chloroform-methanol extraction procedure (Folch et al., 1957). Following lipid extraction, fatty acids (FA) were quantified as methyl esters (FAME) using a gas chromatograph GC Trace 2000 (ThermoQuest EC Instruments) equipped with a flame ionisation detector $\left(260^{\circ} \mathrm{C}\right)$ and a fused silica capillary Column (Zebron ZB-88, Phenomenex, Torrance, CA, USA) with a $100 \mathrm{~m} \times 0.25 \mathrm{~mm} \times 0.20 \mu \mathrm{m}$ film thickness. Helium was used as carrier gas. The oven temperature program was $100^{\circ} \mathrm{C}$ for $5 \mathrm{~min}$ then increasing at $4^{\circ} \mathrm{C} / \mathrm{min}$ up to $240^{\circ} \mathrm{C}$ where it was maintained for $30 \mathrm{~min}$. Results were expressed as percentage of the total FA identified. To assess the nutritional implications, the ratio of $n-6$ to n-3 FA (n-6/n-3) and the ratio of polyunsaturated FA (PUFA) to saturated FA (SFA) $(\mathrm{P} / \mathrm{S})$ were calculated. Moreover, the fat quality indexes (atherosclerotic index (AI) and thrombogenic index (TI)) were calculated, according to the formulas suggested by Ulbricht and Southgate (1991):

$$
\begin{gathered}
\mathrm{AI}=[12: 0+(4 \times 14: 0)+16: 0] /[\mathrm{n}-6 \text { PUFA }+\mathrm{n}-3 \text { PUFA }+ \text { MUFA }] \\
\mathrm{TI}=[14: 0+16: 0+18: 0] /[(0.5 \times \text { MUFA })+(0.5 \times \mathrm{n}-6 \text { PUFA })+(3 \times \mathrm{n}-3 \text { PUFA })+ \\
(\mathrm{n}-3 \text { PUFA } / \mathrm{n}-6 \text { PUFA })]
\end{gathered}
$$

\section{Histological analyses}

Directly after euthanasia the samples of the dorsal rectus muscle (Musculus rectus dorsalis) were taken for histological analyses. Each sample was taken from individual fish, thus sample $n$ of the samples represents $n$ of the fish ( $n=16 /$ treatment). Collected samples were frozen in liquid nitrogen at approximately $-196^{\circ} \mathrm{C}$ until processed in a cryostat (Thermo Shandon/Thermo Fisher Scientific, UK). Histological analyses were conducted at the Bydgoszcz University of Science and Technology (Poland). The muscle was cut into $10 \mu \mathrm{m}$ sections using a cryostat. The material 
prepared in this way was subjected to HE (hematoxylin and eosin) staining to assess fibre diameter, fibre density and histopathological changes, red oil staining to determine intramuscular fat content, and NADH-TR (tetrazolium reductase) activity to distinguish muscle fibre types differing in enzymatic activity. Muscle tissue image recording was performed using a NIKON Ci-L microscope equipped with a NIKON DS-Fi3 camera and NIS ELEMENTS software, which was used to measure fibre diameter and fibre density, and to determine the extent of histopathological changes such as giant fibres and fibre necrosis with phagocytosis per $0.5 \mathrm{~mm}^{2}$. Connective tissue hypertrophy was determined as follows: 0 - no hypertrophy, $1+$ hypertrophy.

\section{Statistical analyses}

Statistical calculations were made using STATISTICA 13.1 software (Dell, Round Rock, TX, USA, 2018). Data were tested for normality by the Shapiro-Wilk test and for homogeneity of variances by use of the Levene's test. Growth parameters were calculated for each replicate ( 4 fish for pond, $n=4$ ). Four fish per pond were collected for chemical and histological analyses (16 fish for each treatment, $n=16$ ). The statistically significant difference (at $\mathrm{P} \leq 0.05)$ between treatments was checked using one-way analysis of variance (ANOVA) followed by Duncan's multiple range tests.

\section{Results}

\section{Nutritional composition}

Total lipids (TL), total cholesterol (TCH) content and fatty acid (FA) composition are reported in Table 2. Meat samples from fish fed 1\% of GOS (group B1) had higher $(\mathrm{P}<0.05)$ TL content compared with the $\mathrm{B} 2$ group $(2 \%$ of prebiotics $)$ but not with respect to the $\mathrm{C}$ group $(\mathrm{P}>0.05)$; similarly, no significant differences in fat content $(\mathrm{P}>0.05)$ were found between $\mathrm{C}$ and $\mathrm{B} 2$ groups. TCH content determined in the present study (ranging from 42.02 to $45.83 \mathrm{mg} / 100 \mathrm{~g}$ ) was not affected by prebiotic treatment $(\mathrm{P}>0.05)$. In the present study, saturated fatty acids (SFA), monounsaturated fatty acids (MUFA) and polyunsaturated fatty acids (PUFA) percentages of the total lipid were not affected $(\mathrm{P}>0.05)$ by prebiotic treatment. Dietary inclusion of $1 \%$ or $2 \%$ GOS significantly affected $(\mathrm{P}<0.05)$ content of myristic $(\mathrm{C} 14: 0)$, palmitoleic (C16:1 n-7), stearic (C18:0), linoleic (C18:2 n-6), arachidonic (C20:4 n-6) and total n-6 fatty acids. Myristic acid (C14:0) was significantly lower in B1 and B2 groups $(\mathrm{P}<0.05)$ compared to the control group. Furthermore, stearic acid $(\mathrm{C} 18: 0)$ was significantly lower in the $\mathrm{B} 1$ and the control groups than in the $\mathrm{B} 2$ group $(\mathrm{P}<0.05)$. For individual MUFA values, palmitoleic acid (C16:1 n-7) was significantly higher $(\mathrm{P}<0.05)$ in the meat of group B1 compared to those of the control and B2 groups, whereas for the individual PUFA acid, linoleic acid (C18:2 n-6) results were lower in the $\mathrm{B} 1$ and $\mathrm{B} 2$ groups compared with the control group $(\mathrm{P}<0.05)$, and arachidonic acid $(C 20: 4 n-6)$ was significantly higher $(P<0.05)$ in the B2 group compared to the $\mathrm{B} 1$ and control groups. 
Table 2. Effect of GOS administration on total lipids and cholesterol contents, fatty acid composition ( $\%$ of total fatty acids), and nutritional ratios in meat of common carp (Cyprinus carpio)

\begin{tabular}{|c|c|c|c|c|c|}
\hline \multirow[b]{2}{*}{ Items } & \multicolumn{3}{|c|}{ Experimental groups } & \multirow[b]{2}{*}{ SEM } & \multirow[b]{2}{*}{ P-value } \\
\hline & $\begin{array}{c}\mathrm{C} \\
\mathrm{n}=16\end{array}$ & $\begin{array}{c}\mathrm{B} 1 \\
\mathrm{n}=16\end{array}$ & $\begin{array}{c}\mathrm{B} 2 \\
\mathrm{n}=16\end{array}$ & & \\
\hline Total lipids (g/100 g) & $2.47 \mathrm{ab}$ & $3.21 \mathrm{a}$ & $2.23 \mathrm{~b}$ & 0.17 & 0.046 \\
\hline Total cholesterol (mg/100 g) & 42.02 & 45.83 & 44.55 & 0.78 & 0.127 \\
\hline \multicolumn{6}{|l|}{ Fatty acid } \\
\hline $\mathrm{C} 14: 0$ & $1.39 \mathrm{a}$ & $1.18 \mathrm{~b}$ & $1.12 \mathrm{~b}$ & 0.04 & 0.006 \\
\hline $\mathrm{C} 16: 0$ & 20.19 & 20.87 & 20.42 & 0.16 & 0.220 \\
\hline C16:1n-7 & $6.21 \mathrm{~b}$ & $6.57 \mathrm{a}$ & $5.94 \mathrm{~b}$ & 0.11 & 0.034 \\
\hline $\mathrm{C} 18: 0$ & $4.53 \mathrm{~b}$ & $4.70 \mathrm{~b}$ & $5.06 \mathrm{a}$ & 0.06 & 0.001 \\
\hline C18:1n-9 & 44.61 & 44.78 & 44.35 & 0.42 & 0.917 \\
\hline $\mathrm{C} 18: 2 \mathrm{n}-6$ & $14.02 \mathrm{a}$ & $12.93 \mathrm{~b}$ & $12.92 \mathrm{~b}$ & 0.14 & 0.001 \\
\hline C18:3 n-6 & 2.35 & 2.08 & 2.17 & 0.06 & 0.197 \\
\hline C20:1n-9 & 0.51 & 0.53 & 0.68 & 0.04 & 0.110 \\
\hline $\mathrm{C} 20: 4 \mathrm{n}-6$ & $1.50 \mathrm{~b}$ & $1.78 \mathrm{~b}$ & $2.15 \mathrm{a}$ & 0.13 & 0.045 \\
\hline C20:5 n-3 & 0.82 & 0.83 & 0.88 & 0.05 & 0.887 \\
\hline $\mathrm{C} 22: 5 \mathrm{n}-3$ & 0.73 & 0.53 & 0.63 & 0.05 & 0.287 \\
\hline $\mathrm{C} 22: 6 \mathrm{n}-3$ & 3.14 & 3.22 & 3.68 & 0.19 & 0.385 \\
\hline \multicolumn{6}{|l|}{ Partial sum } \\
\hline$\Sigma$ SFA & 26.11 & 26.75 & 26.60 & 0.16 & 0.241 \\
\hline ¿MUFA & 51.33 & 51.88 & 50.97 & 0.42 & 0.649 \\
\hline$\Sigma$ PUFA & 22.56 & 21.37 & 22.43 & 0.33 & 0.323 \\
\hline Total n-6 & $17.87 \mathrm{a}$ & $16.79 \mathrm{~b}$ & $17.24 \mathrm{ab}$ & 0.18 & 0.043 \\
\hline Total n-3 & 4.59 & 4.57 & 5.19 & 0.26 & 0.563 \\
\hline \multicolumn{6}{|l|}{ Nutritional ratios } \\
\hline$n-3 / n-6$ & 0.26 & 0.27 & 0.30 & 0.01 & 0.562 \\
\hline$n-6 / n-3$ & 3.89 & 3.67 & 3.32 & 0.19 & 0.338 \\
\hline PUFA/SFA & 0.86 & 0.80 & 0.84 & 0.01 & 0.137 \\
\hline AI & 0.35 & 0.35 & 0.34 & 0.00 & 0.143 \\
\hline TI & 0.54 & 0.56 & 0.53 & 0.01 & 0.371 \\
\hline
\end{tabular}

C - Control; B1 - $1 \% \mathrm{Bi}^{2} \operatorname{tos}^{\circledR}, \mathrm{B} 2-2 \% \mathrm{Bi}^{2} \operatorname{tos}^{\circledR}$.

$\mathrm{SEM}$ - standard error mean.

$\mathrm{a}, \mathrm{b}-$ values significantly differ at $\mathrm{P}<0.05$ level.

Fish fed a diet of $1 \%$ of GOS reduced the content of total n-6 FA compared with the control group $(\mathrm{P}<0.05)$; the intermediate value was shown with $2 \%$ of GOS $(\mathrm{P}>0.05)$. A higher amount of n-6 FA in the control group owes itself to the precursor of the n-6 family, the linoleic acid, quantitatively the most concentrated n-6 PUFA. Significantly, no differences were found between the experimental groups for the total amount of n-3 long chain PUFA, as well as for indexes for human health n-3/n-6, 
n-6/n-3 and PUFA/SFA ratios. In the present study, no statistically significant differences between the groups were found for AI and TI.

Taking into account the general FA profile, total MUFA were the most abundant FA (ranging from 50.97 to $51.88 \%$ ), followed in descending order by SFA (ranging from 26.11 to $26.75 \%$ ) and PUFA (ranging from 21.37 to $22.46 \%$ ). Quantitatively, the oleic acid (C18:1 n-9) was the most concentrated fatty acid, followed by palmitic (C16:0), linoleic acid (C18:2 n-6) and palmitoleic acid (C16:1 n-7). Regarding the composition of the single PUFA n-3, docosahexaenoic acid (DHA, C22:6 n-3) was the highest of the fatty acids.

\section{Histological analyses}

The results of muscle histological measurements are shown in Table 3.

Table 3. The effect of GOS on histological measurements of muscle fibres of common carp (Cyprinus carpio)

\begin{tabular}{|c|c|c|c|c|c|}
\hline Items & $\begin{array}{c}C \\
n=16\end{array}$ & $\begin{array}{c}B 1 \\
n=16\end{array}$ & $\begin{array}{c}\mathrm{B} 2 \\
\mathrm{n}=16\end{array}$ & SEM & P-value \\
\hline Fibre diameter $(\mu \mathrm{m})$ & 48.32 & 50.18 & 52.14 & 0.816 & 0.144 \\
\hline $\begin{array}{l}\text { Muscle fibre density } \\
\text { (fibres } \mathrm{n} / 1.5 \mathrm{~mm}^{2} \text { ) }\end{array}$ & 106.60 & 117.00 & 117.00 & 3.703 & 0.422 \\
\hline $\begin{array}{l}\text { Muscle fibre type (\%) } \\
\alpha \mathrm{W}\end{array}$ & 100 & 100 & 100 & - & - \\
\hline Normal fibres ( $\%)$ & $93.81 \mathrm{~b}$ & $95.06 \mathrm{ab}$ & $96.31 \mathrm{a}$ & 0.004 & 0.021 \\
\hline Fibre atrophy $(\%)$ & $3.23 \mathrm{a}$ & $2.73 \mathrm{ab}$ & $1.58 \mathrm{~b}$ & 0.003 & 0.016 \\
\hline Fibre splitting (\%) & 2.96 & 2.22 & 2.11 & 0.002 & 0.208 \\
\hline Connective tissue hypertrophy (\%) & 80.00 & 54.00 & 38.00 & & \\
\hline
\end{tabular}

C-Control; B1 - 1\% $\mathrm{Bi}^{2} \operatorname{tos}{ }^{\circledR}, \mathrm{B} 2-2 \% \mathrm{Bi}^{2} \operatorname{tos}{ }^{\circledR}$.

$\mathrm{SEM}$ - standard error mean.

$\mathrm{a}, \mathrm{b}-$ values significantly differ at $\mathrm{P}<0.05$ level.

Analyses showed muscle is characterised by a glycolytic metabolism, 100\% white fibres $-\alpha \mathrm{W}$, because the activity of the oxygen enzyme (oxidoreductase) tetrazolium reductase has not been shown (Figure $1 \mathrm{~A}$ ). Red oil staining showed that intramuscular fat is distributed around the muscle fibres (Figure $1 \mathrm{~B}$ ). Figure $1 \mathrm{C}$ showed histopathological changes. It can be seen that as the concentration of GOS added to the feed increases, the percentage of normal fibres increases $(\mathrm{P}<0.05)$. The group of animals receiving $2 \%$ transgalacto-oligosaccharide was characterised by the highest percentage of normal fibres (96.31\%) compared to the control group (93.81\%). Statistical analyses showed a significantly lower percentage of atrophy fibres in the groups supplemented with prebiotic $(\mathrm{P}<0.05)$. The most favourable values were obtained in the research group supplemented with a $2 \%$ prebiotic (group B2 $-1.58 \%$ ) compared to the control group (3.23\%). Similar differences were noted for splitting, but statistical analyses did not confirm this. The microscopic image of the muscle showed no changes such as giant fibres or fibre necrosis with phagocytosis. Figure $1 \mathrm{D}$ showed connective tissue. It was observed that as the prebiotic added was increased, the connective tissue hypertrophy decreased. 

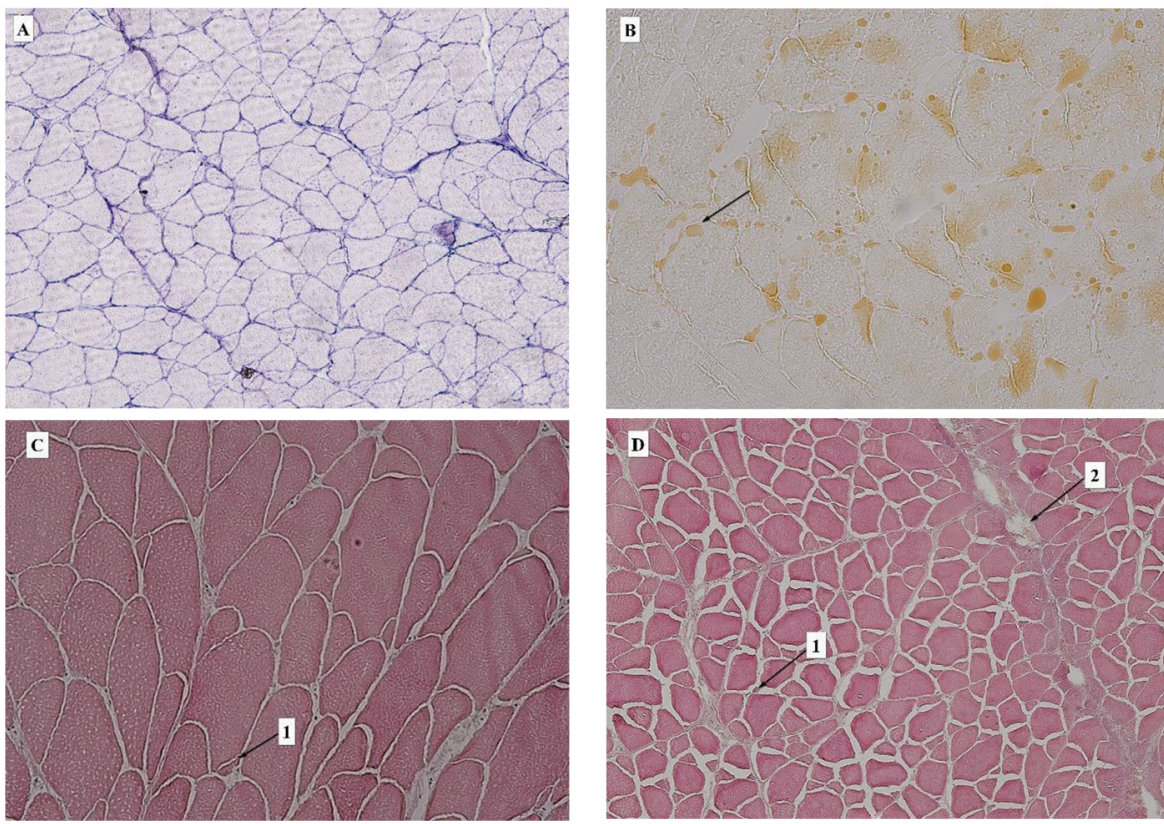

Figure 1. (A) Muscle fibre types: $\alpha \mathrm{W}$ (glycolytic) NADH-TR (NADH-tetrazolium reductase) activity staining, magnification $\times 100$; (B) intramuscular fat (arrow), red oil staining, magnification $\times 200$; $(C)$ fibre splitting -1 (arrows), hematoxylin and eosin (HE) staining, magnification $\times 200$; (D) atrophy fibre -1 (arrow), connective tissue overgrowth -2 (arrow), hematoxylin and eosin (HE) stain, magnification $\times 100$

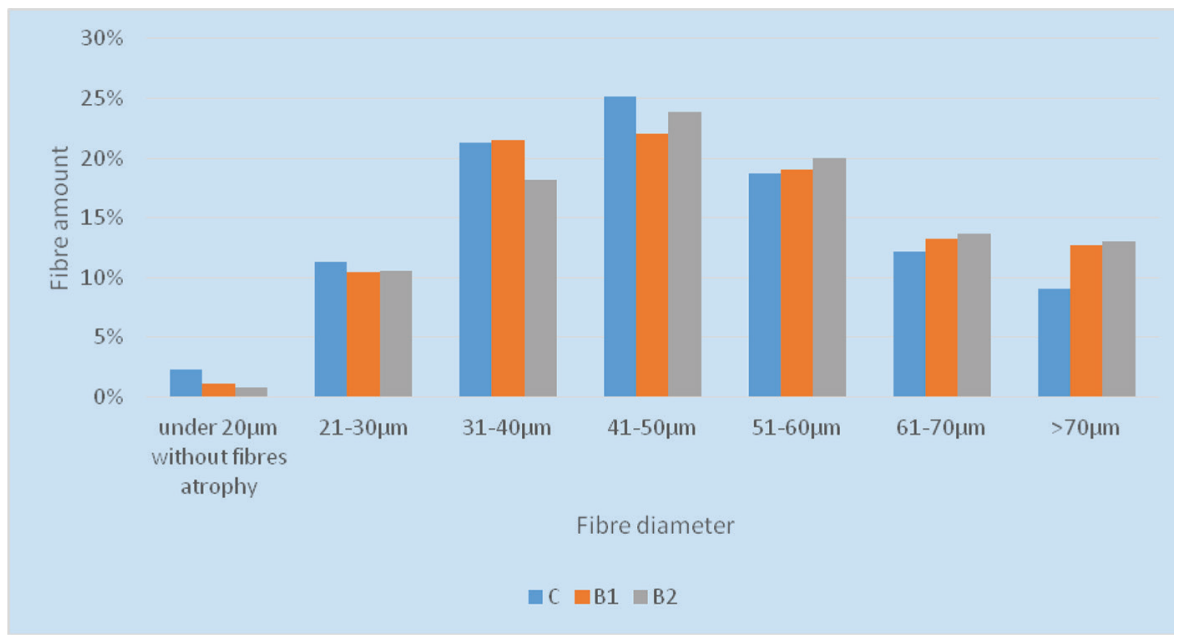

Figure 2. Cross sectional area of white muscles without fibres atrophy $\left(\mathrm{C}-\mathrm{Control}\right.$; $\mathrm{B} 1-1 \% \mathrm{Bi}^{2} \operatorname{tos}^{\circledR}$, $\left.\mathrm{B} 2-2 \% \mathrm{Bi}^{2} \operatorname{tos}^{\circledR}\right)$ 
Due to the presence of only white glycolytic fibres (Figure $1 \mathrm{~A}$ ), the diameters of these fibres were analysed. In both the control group and the B1 group we observed the largest percentage share of white muscle fibre diameters in the range of 31-40 $\mu \mathrm{m}$ and 41-50 $\mu \mathrm{m}$, respectively (Figure 2). On the other hand, increasing the prebiotic addition to $2 \%$ (group B2) resulted in an increase in thickness of white muscle fibres in the 51-60 $\mu \mathrm{m}$ and $41-50 \mu \mathrm{m}$ range. In all three groups, the lowest percentage was white muscle fibres, which was in the range $<20 \mu \mathrm{m}(1-2 \%)$. However, the analyses showed no statistically significant differences in the discussed ranges.

\section{Discussion}

\section{Nutritional composition}

Lipids extracted from fatty fish meat, which includes common carp, are predominantly composed of triacylglycerols. As many results confirm, GOS is able to decrease serum triacylglycerol concentrations by enhancing lipoprotein catabolism. The triacylglycerol-lowering action of GOS is due to the inhibition of lipogenic enzymes, e.g., acetyl-CoA carboxylase (ACC), fatty acid synthase (FAS), malic enzyme (ME), ATP citrate lyase (ACLY), and glucose-6-phosphate dehydrogenase (G6PD) (Guerreiro et al., 2017 a; Ulbricht and Southgate, 1991; Delzenne and Kok, 2001; Delzenne et al., 2002; Wang et al., 2016 a). As the analyses by Guerreiro et al. (2015) showed, lipogenic enzyme activities (FAS, ME and G6PD) were lower in European sea bass (Dicentrarchus labrax) that were fed diets including xylooligosaccharides (XOS, Qingdao, FTZ United International Inc., China) than in the other groups. The lipid-lowering effect of GOS may result from the inhibition of the expression of genes and proteins, including liver enzymes responsible for glucose metabolism, which reduces the accumulation of fat (Sun et al., 2017). In this study we confirmed that GOS supplementation did not affect the total lipid (TL) level in the meat of the analysed common carp. The highest TL level was determined in the B1 and the lowest in the B2 group, but neither B1 nor B2 groups were different from the control group. The same results were confirmed by Dimitroglou et al. (2010) for gilthead seabream (Sparus aurata) fed with a diet supplemented with MOS. The absence of a lipid-lowering effect of GOS used in the present study may result from the fish adapting to the experimental diets. As Guerreiro et al. (2017 b) confirmed, it is possible that fish gut bacteria community and digestive enzymatic activity had to adapt to the dietary modification. Results of studies on the effect of prebiotics on animal health are often contradictory given that several factors may affect the fermentability of prebiotics. One of these factors is the type and dose of the prebiotic. The study of Biggs et al. (2007) demonstrated that excessively high prebiotic dose may have a negative impact on the gastrointestinal system and may delay the growth of animals. This could be related to the inability of gut bacteria to ferment the high amount of prebiotic provided in the diet. The opposite hypothesis is that GOS, as a prebiotic with a low degree of polymerisation (PD), at a dose of $1 \%$ and $2 \%$, was too weak in relation to the enzymes responsible for lipid metabolism. Our fat results 
are to the contrary to those of Munir et al. (2016), who found that GOS (Vivinal ${ }^{\circledR}$, Friesland Campina Domo, The Netherlands) reduced lipid amount (about 1.4\%) compared with the control group of snakehead (Channa striata) fingerlings. In turn, Mansour et al. (2012) observed increased total lipid in giant sturgeon (Huso huso) fed with a diet supplemented with MOS (ActiveMOS ${ }^{\circledR}$, Biorigin, Lencois Paulista, Säo Paulo, Brazil), which may be beneficial from a consumer point of view, because intramuscular fat can have a positive effect on the juiciness and taste of meat.

Content of the cholesterol in the meat depends on the fish species (species feature) (Moreira et al., 2001), is not correlated with fat content (Piironen et al., 2002), and is affected by several factors, among them the PUFA content (Guillen et al., 2019; Kinsella, 1986). The total cholesterol (TCH) content determined in the present study was not affected by prebiotic treatment $(\mathrm{P}>0.05)$. As numerous studies confirm, synthetically produced prebiotics may increase the production of acetate, propionate and butyrate (Jackson and Lovegrove, 2012). Analysis of the hipolipidemic properties of short-chain FOS in humans confirmed that propionate inhibits cholesterol synthesis by inhibiting both 3-hydroxy-3-methylglutaryl-CoA (HMGCoA) synthase and HMG-CoA reductase (Bornet et al., 2002). In vitro studies of rat hepatocytes confirmed inhibition of cholesterol synthesis by prebiotics due to the impaired absorption of acetate by liver cells (Jackson and Lovegrove, 2012). To better understanding the effect of the prebiotic supplement on cholesterol homeostasis, it would be necessary to analyse the expression of genes involved in bile acid synthesis and the synthesis, esterification, and excretion of cholesterol. The desirability of such studies has been confirmed by Zhu et al. (Zhu et al., 2018), who analysed the expression of genes responsible for cholesterol metabolism in rainbow trout (Oncorhynchus mykiss) fed a plant-based diet.

The fatty acid (FA) proportion of meat is considered an important index for meat quality. Fish fat is characterised by a significant amount of PUFA and is commonly recognised as the main source of n-3 FA. Fish meat is a rich source of a mixture of eicosapentaenoic acid (EPA) and docosahexaenoic acid (DHA), but the levels of these dietary nutrients vary appreciably among different fish species (Kris-Etherton et al., 2000; Steffens and Wirth, 2005). To our knowledge, there is very little information in the literature on the effect of prebiotics on the fatty acid profile in fish meat.

In the present study, we showed that GOS supplementation affected myristic (C14:0), palmitoleic (C16:1 n-7), stearic (C18:0), linoleic (C18:2 n-6), arachidonic (C20:4 n-6) and total n-6 FA percentages, but had no stimulating effect on other FA profiles. This confirms the hypothesis that diet supplementation with prebiotic may modify the expression of genes responsible for the expression of lipogenic enzymes. Studies of rats fed a mixture of inulin and oligofructose have shown that it caused a reduction in body weight gain and visceral fat, which may be significant in the regulation of fatty acid metabolism in the liver. An effective inhibitor of de novo fatty acid synthesis is propionate, a product of prebiotic metabolism (Sun et al., 2017; Demigné et al., 1995). The present study confirmed that GOS supplementation significantly reduced myristic acid in the $\mathrm{B} 1$ and $\mathrm{B} 2$ groups, and increased stearic acid in the B2 group compared to groups B1 and C. Myristic acid causes a significant increase in total cholesterol and LDL content in serum, therefore the obtained result 
seems to be a beneficial effect of GOS supplementation (Table 4). Stearic acid, in contrast to other saturated fatty acids (such as lauric, myristic and palmitic acids), does not increase serum cholesterol, and therefore does not increase the risk of coronary heart disease. This is because stearic acid quickly turns into monounsaturated oleic acid (C18:1 n-9). Piccolo et al. (2013) reported that MOS diet (ECHOMOS; Mazzoleni Prodotti Zootecnici, Cologno al Serio, BG, Italy) seemed to improve the synthesis of some fatty acids such as C16:0, C18:0 and C18:1n-9 in the meat of sharpsnout seabream (Diplodus puntazzo).

From a physiological point of view, elongated and unsaturated fatty acid derivatives are more important than their parent fatty acids. These acids are arachidonic acid (AA) in the case of the n-6 series and eicosapentaenoic acid (EPA) and docosahexaenoic acid (DHA) in the case of the n-3 series (Steffens and Wirth, 2005). Freshwater fish thanks to their $\Delta 5$ and $\Delta 6$ desaturase systems are capable of elongation and desaturation of linoleic acid and $\alpha$-linolenic acid, while the marine fish have a limited ability to synthesise long-chain polyunsaturated fatty acids from n-6 and n-3 series (Steffens and Wirth, 2007). Prebiotics produce changes in the global composition of the intestine flora and affect its growth and metabolic activities. This can increase the levels of long-chain PUFAs as bacteria have the enzymes necessary to elongate and desaturate fatty acids (Macfarlane et al., 2006). In our studies we confirmed significantly higher content of arachidonic acid in the B2 group compared to $\mathrm{B} 1$ and $\mathrm{C}$ groups (Table 2). This is probably a confirmation of desaturase and elongase activities. Kindt et al. (2018) confirmed that the gut microbiota promotes hepatic fatty acid desaturation and elongation in mice $(\Delta-9$ desaturation of palmitate [C16:0] to palmitoleate [C16:1 n-7] and elongation of $\alpha$-linolenic [C18:3 n-6] to dihomo- $\gamma$-linolenic acid [DGLA, C20:3 n-6]). The linoleic-lowering effect of GOS confirmed in our research is difficult to explain due to the lack of available data. Piccolo et al. (2012) showed no statistically significant differences in the content of this acid between groups treated with prebiotics (mannan oligosaccharide and inulin).

Some studies reported that prebiotics can alter lipid metabolism and improve the ratio of PUFA/SFA and n-3/n-6 in chicken meat (Velasco et al., 2010; Tavaniello et al., 2018), which is beneficial to human health. In our study, we confirm no significant differences in terms of these ratios between GOS-treated and control groups. Despite the fact that $1 \%$ GOS supplementation resulted in a lower total $\mathrm{n}-6$ FA content (the negative effect is marked in Table 4), the analyses confirmed the appropriate n-6/n-3 ratio. Similarly, no statistically significant differences were found for the atherogenic index (AI) and the thrombogenic index (TI), which is the criteria for evaluating the level and interrelation through which some fatty acids may have atherogenic or thrombogenic properties, respectively. Our results are in line with Piccolo et al. (2013), who confirmed no significant differences in AI and TI content between groups. AI and TI indexes express the proportion of selected saturated to unsaturated fatty acids, and are considered better indicators of atherogenicity and thrombogenicity than the PUFA/SFA ratio. It is assumed that the lower their value, the more beneficial the fatty acid profile in terms of health for the consumer (Ulbricht and Southgate, 1991). 


\section{Histological analyses}

Individual muscle fibres are the basic unit of muscle tissue. Depending on the metabolic and structural properties, red and white fibres can be distinguished. White fibres have a rapid shrinkage rate but are prone to fatigue. Red fibres shrink more slowly with less force and are resistant to fatigue. In red fibres, the main metabolic pathway is aerobic change and anaerobic change in white fibres. Carp muscle masses are mainly made of white, glycolytic fibres. A fish that increases its body weight increases primarily the amount of white fibres, which can constitute about $90 \%$ of the total volume of muscle tissue. Analyses of the tested material showed a $100 \%$ predominance of white muscle fibres, which is close to the results obtained by Zimmerman and Lowery (1999), Weatherley and Gill (1989), and Karahmet et al. (2014). Due to the $100 \%$ content of white muscle fibres, the diameters of normal white muscle normal fibres were analysed and then assigned to appropriate classes. Karahmet et al. (2014) showed that the average diameter of muscle fibres in rainbow trout (Oncorhynchus mykiss) is in the range 31-40 $\mu \mathrm{m}$ and $41-50 \mu \mathrm{m}$, whereas in brown trout (Salmo trutta) and alpine trout (Salvelinus alpinus) the average diameter is at intervals of $21-30 \mu \mathrm{m}$ and $31-40 \mu \mathrm{m}$. These studies are in line with ours, in which the largest amount of muscle fibres was assigned to the class of muscle fibres with a diameter of 31-40 $\mu \mathrm{m}$ and 41-50 $\mu \mathrm{m}$. In fish, we observe both hypertrophic and hyperplastic growth of muscle fibres. Hyperplastic growth is regulated mainly by the Myogenic Regulatory Factor myoD, for the proliferation of myoblasts. The expression of the myoD gene in muscle fibres is associated with intense proliferation of satellite cells associated with intense hyperplasia and the mechanisms of hypertrophy (Carani et al., 2013). Both hypertrophic and hyperplastic growth result in a large variety of muscle fibre diameters. The large variety of muscle fibre diameters that we also observe in our research gives the muscles a mosaic-like appearance. This is characteristic of fish meat, as demonstrated by Johnston et al. (1975) and Listrat et al. (2016). Priester et al. (2011) also showed that as the size of the black seabass (Centropristis striata) increased, the average diameter of the muscle cells increased proportionally from $36 \mu \mathrm{m}$ to $280 \mu \mathrm{m}$. There were no statistically significant differences in the diameter and density of muscle fibres between the experimental groups. These results differ from those obtained by Rabah (2005) and Johnston et al. (1975). Johnston et al. (1975) stated that as the total number of white muscle fibres in the Atlantic salmon (Salmo salar) increased, their density also decreased. This study also showed a statistically significant reduction in the percentage of atrophy fibres $(\mathrm{C}-3.23 \%$; B2 $-1.58 \%$ ). Atrophy fibres arise as a result of, e.g., aging and hereditary muscle disorders, but also of hypoxia, or deficiency of ingredients in the food ration, e.g., vitamin E or selenium (Hugh et al., 1976). Wang et al. (2016 b) demonstrated the effect of vitamin E deficiency on muscle myopathies as manifested by muscle atrophy. Moreover, hypoxic stress or an increased presence of copper may also contribute to the development of muscle fibre atrophy (Harper and Wolf, 2009; Maharajana et al., 2016). In muscles which we studied, the experimental factor reduced the number of atrophy fibres. The larger diameter of the muscle fibres was observed in the research groups, yet the higher fibre density per unit area is associated with the smaller thickness of the connective tissue. A smaller amount of connective tissue was observed 
in the research groups. Hypertrophy of connective tissue can exert pressure on the surrounding blood vessels, which in turn can contribute to a decrease in blood supply to the fibres, and thus to degenerative changes.

In many fish, the number of muscle fibres increases throughout the life cycle (Sun et al., 2017). Therefore, GOS supplementation in the diet can promote the development of fish muscles and contribute to the improvement of meat quality, although the mechanism is still unknown (Table 4).

Table 4. Effect of GOS supplementation on lipid metabolism and meat microstructure of common carp (Cyprinus carpio) compared to the $\mathrm{C}$ group

\begin{tabular}{ll|c}
\hline \multicolumn{1}{c|}{ Parameters* } & B1 & B2 \\
\hline Nutritional composition & & \pm \\
TL & \pm & + \\
C14:0 & + & \pm \\
C16:1 n-7 & + & + \\
C18:0 & \pm & - \\
C18:2 n-6 & - & + \\
C20:4 n-6 & \pm & \pm \\
total n-6 & - & \\
Histological analyses & & + \\
normal fibres & \pm & + \\
fibre atrophy & \pm & \\
\hline
\end{tabular}

*parameters for which statistically significant differences between treatment groups were found at $\mathrm{P}<0.05$. $\mathrm{B} 1-1 \% \mathrm{Bi}^{2}$ tos ${ }^{\mathbb{R}}, \mathrm{B} 2-2 \% \mathrm{Bi}^{2} \operatorname{tos}^{\mathbb{R}}$.

Positive effect $(+)$, negative effect $(-)$ and neutral effect $( \pm)$ of GOS compared to the control group.

\section{Conclusions}

The results of the present study revealed that prebiotics could be a potential dietary additive for farmed common carp. GOS had a positive effect on some muscle fatty acid profiles and stimulated conversion of fatty acids to their long-chain unsaturated derivatives in the case of the $n-6$ series (C20:4 n6). That there were no differences in the total cholesterol content between the experimental groups may indicate maintenance of the metabolic balance of this sterol due to the prebiotic used. The supplementation of feed with $2 \%$ GOS positively affected meat microstructure and slightly increased the percentage of normal fibres, while it slightly decreased the percentage both of split values and of fibre atrophy. Further research on the effects of prebiotics on lipid metabolism should be carried out because this topic is not fully explored, especially in the case of the fatty acid profile. Research on the effect of prebiotics on different species of fish on the basis of a comparative study will help identify the best prebiotic to change the intestinal microflora of the species.

\section{Conflicts of interest}

The authors declare no conflict of interest. 


\section{References}

A khter N., Wu B., M e m on A.M., M o h s in M. (2015). Probiotics and prebiotics associated with aquaculture: A review. Fish Shellfish Immunol., 45: 733-741.

B a n e r j e e G., R a y A.K. (2017). Bacterial symbiosis in the fish gut and its role in health and metabolism. Symbiosis, 72: 1-11.

B igg s P., P a r s on s C.M., F a h e y G.C. (2007). The effects of several oligosaccharides on growth performance, nutrient digestibilities, and cecal microbial populations in young chicks. Poultry Sci., 86: $2327-2336$.

Bogucka J., Miguel Ribeiro D., Da Costa R.P.R., Bednarczyk M. (2018). Effect of synbiotic dietary supplementation on histological and histopathological parameters of Pectoralis major muscle of broiler chickens. Czech. J. Anim. Sci., 63: 263-271.

B ornet F.R.J., B roun s F., Ta sh i ro Y., D u vill i e r V. (2002). Nutritional aspects of short-chain fructooligosaccharides: natural occurrence, chemistry, physiology and health implications. Dig. Liver Dis., 34: 6111-6120.

Ca o H., Yu R., Zhang Y., Hu B., Jian S., Wen Ch., Kajbaf K., Kumar V., Yang G. (2019). Effects of dietary supplementation with $\beta$-glucan and Bacillus subtilis on growth, fillet quality, immune capacity, and antioxidant status of Pengze crucian carp (Carassius auratus var. Pengze). Aquaculture, 508: 106-112.

Carani F.R., Da Silva Duran B.O., Gutierrez De Paula T., Pereira Piedade W., D a 1 - P a i-Silva M. (2013). Morphology and expression of genes related to skeletal muscle growth in juveniles of pirarucu (Arapaima gigas, Arapaimatidae, Teleostei). Acta Sci., Anim. Sci., 35: 219-226.

D aw o o d M.A.O., K os hi o S. (2016). Recent advances in the role of probiotics and prebiotics in carp aquaculture: A review. Aquaculture, 454: 243-251.

Delzenne N.M., Kok N. (2001). Effects of fructans-type prebiotics on lipid metabolism. Am. J. Clin. Nutr., 73: 456S-458S.

D e lzenne N.M., D a u bi o u 1 C., N e y rinck A., L a s a M., Taper H.S. (2002). Inulin and oligofructose modulate lipid metabolism in animals: review of biochemical events and future prospects. Brit. J. Nutr., 87: 255-259.

De Silva S.S., Anders on T.A. (1995). Fish nutrition in aquaculture. Chapmann \& Hall, London, $319 \mathrm{pp}$.

Demigné C., Morand C., Levrat M., B esson C., Moundras C., Rémés y C. (1995). Effect of propionate on fatty acid and cholesterol synthesis and on acetate metabolism in isolated rat hepatocytes. Brit. J. Nutr., 74: 209-219.

Dimitroglou A., Merrifield D.L., Spring P., Swe etman J., Moate R., Davies S.J. (2010). Effects of mannan oligosaccharide (MOS) supplementation on growth performance, feed utilisation, intestinal histology and gut microbiota of gilthead seabream (Sparus aurata). Aquaculture, 300: 182-188.

Ebrahimi G., Ouraji H., Khalesi M., Sudagar M., Barari A., Zarei Dangesarak i M., J a n i K halili K. (2012). Effects of a prebiotic, Immunogen ${ }^{\circledR}$, on feed utilization, body composition, immunity and resistance to Aeromonas hydrophila infection in the common carp Cyprinus carpio (Linnaeus) fingerlings. J. Anim. Physiol. Anim. Nutr., 96: 591-599.

FAO (2020). Fisheries and Aquaculture, National Aquaculture Sector Overview - Poland.

F ol ch J., L e e s M., S l o a n e - S t a n l e y G.H. (1957). A simple method for the isolation and purification of total lipids from animal tissues. J. Biol. Chem., 226: 497-509.

Gibs on G.R., Hutkins R., S anders M.E., Pre s c ot t S.L., R e i m e r R.A., S a $1 \mathrm{~m}$ in en S.J., S c ot t K., S t an ton C., S w an s on K.S., C a n i P.D., Verbe ke K., R e id G. (2017). Expert consensus document: the International Scientific Association for Probiotics and Prebiotics (ISAPP) consensus statement on the definition and scope of prebiotics. Nat. Rev. Gastroenterol. Hepatol., 14: 491 .

Godfray H.C.J., Beddington J.R., Crute I.R., Haddad L., Lawrence D., Muir J.F., Pretty J., Robins on S.R., Thomas S.M., Toulmin C. (2010). Food security: the challenge of feeding billion people. Science, 327: 812-818.

Gris d a le-Helland B., Hell and S., G a t l in D. (2008). The effects of dietary supplementation 
with mannanoligosaccharide, fructooligosaccharide or galactooligosaccharide on the growth and feed utilization of Atlantic salmon (Salmo salar). Aquaculture, 283: 163-167.

Guerreiro I., Olivia-Teles A., Enes P. (2015). Improved glucose and lipid metabolism in European sea bass (Dicentrarchus labrax) fed short-chain fructooligosaccharides and xylooligosaccharides. Aquaculture, 441: 57-63.

Guerreiro I., Oliva-Teles A., Enes P. (2017 a). Prebiotics as functional ingredients: focus on Mediterranean fish aquaculture. Rev. Aquacult., 10: 800-832.

Guerreiro I., S erra C.R., P ous ão-Ferreira P., Oliva-Teles A., Enes P. (2017 b). Prebiotics effect on growth performance, hepatic intermediary metabolism, gut microbiota and digestive enzymes of white sea bream (Diplodus sargus). Aquacult. Nutr., 24: 153-163.

Guillen J., Natale F., Carvalho N., Casey J., Hofherr J., Druon J.-N., Martins o h n J.T. (2019). Global seafood consumption footprint. Ambio, 48: 111-122.

H a r p e r C., W o $1 \mathrm{f}$ J.C. (2009). Morphologic effects of the stress response in fish. ILAR J., 50: 387-396.

Hoc quette J.F., Gondret F., B a e z E., M edale F., Jurie C., P e thi ck D.W. (2010). Intramuscular fat content in meat-producing animals: development, genetic and nutritional control and identification of putative markers. Animal, 4: 303-319.

Hoffmann L., Mazurkiewicz J., Florczyk K., Burchardt H. (2017). Using probiotic feed supplements in carp rearing. Komunikaty Rybackie, 2: 14-21.

H o ffmann L., Raw ski M., Nogales - Merida S., Mazurkiewicz J. (2020). Dietary inclusion of Tenebrio molitor meal in sea trout larvae rearing: Effects on fish growth performance, survival, condition, and GIT and liver enzymatic activity. Ann. Anim. Sci, 20: 579-598.

Horváth L., Tamás G., S e g r a ve C. (2002). Carp and pond fish culture, 2nd ed. Blackwell Science: Oxford, UK.

Hose in ifar S.H., Ahmadi A., Raeis i M., Hoseini S.M., Khalili M., Behnamp o u r N. (2016). Comparative study on immunomodulatory and growth enhancing effects of three prebiotics (galactooligosaccharide, fructooligosaccharide and inulin) in common carp (Cyprinus carpio). Aquac. Res., 48: 3298-3307.

Hugh A., Post on Gerald F., Combs Jr., Lou is L. (1976). Vitamin E and selenium interrelations in the diet of Atlantic salmon (Salmo salar): gross, histological and biochemical deficiency signs. J. Nutr., 106: 892-904.

Hus sein M.S., Zaghlol A., Abd El Hakim N.F., El Nawsany M., Abo-State H.A. (2016). Effect of different growth promoters on growth performance, feed utilization and body composition of common carp (Cyprinus carpio). J. Fish Aquat. Sci., 11: 370-377.

J a c k s on K.G., L ove grove J.A. (2012). Impact of probiotics, prebiotics and synbiotics on lipid metabolism in humans. J. Nutr. Health Aging, 1: 181-200.

J o hn s t o n I.A., Ward P.S., G old s p in k G. (1975). Studies on the swimming musculature of the rainbow trout I. Fibre types. J. Fish Biol., 7: 451-458.

Józefiak A., Nogales - Merida S., Rawski M., Kierończyk B., Mazurkiewicz J. (2019). Effects of insect diets on the gastrointestinal tract health and growth performance of Siberian sturgeon (Acipenser baerii Brandt, 1869). BMC Vet. Res., 15: 348.

Karahmet E., Viles A., Katica A., Mlaco N., Toroman A. (2014). Differences between white and red muscle fibres diameter in three salmon fish species. Biotechnol. Anim. Husb., 30: $349-356$.

Kindt A., Liebis ch G., Clavel T., Haller D., Hörmannsperger G., Yoon H., Kolmeder D., S igruener A., Krautbauer S., S e eliger C., Ganzha A., S chweizer S., Morisset R., Strowig T., Daniel H., Helm D., Küster B., Krumsieke J. (2018). The gut microbiota promotes hepatic fatty acid desaturation and elongation in mice. Nat. Commun, 9: 3760 .

K in s e 11 a J.E. (1986). Food component with potential benefits: the n-3 polyunsaturated fatty acids of fish oils. Food Technol., 40: 89-97.

Kris-Etherton P.M., Taylor D.S., Yu-Poth S., Huth P., Moriarty K., Fishell V., Hargrove R.L., Zhao G., Etherton T.D. (2000). Polyunsaturated fatty acids in the food chain in the United States. Am. J. Clin. Nutr., 71: 179-188.

Kurdomanov A., Sirakov I., Stoyanova S., Velichkova K., Nedeva I., Staykov Y. (2019). The effect of diet supplemented with Proviotic ${ }^{\circledR}$ on growth, blood biochemical parameters 
and meat quality in rainbow trout (Oncorhynchus mykiss) cultivated in recirculation system. AACL Bioflux, 12.

L e a f A., K a ng J.X., Xi a o Y.F., B i $11 \mathrm{~m}$ a n G.E. (2003). Clinical prevention of sudden cardiac death by n-3 polyunsaturated fatty acids and mechanism of prevention of arrhythmias by n-3 fish oils. Circulation, 107: 263-264.

Le ary S., Und e rw o o d W., A n th o n y R., Cartne r S. (2013). AVMA Guidelines for the Euthanasia of Animals, 2013 Edition. AVMA, Schaumburg, IL, USA, pp. 67-73.

L evitan E.B., Wolk A., Mittlem an M.A. (2010). Fatty fish, marine $\omega-3$ fatty acids and incidence of heart failure. Eur. J. Clin. Nutr., 64: 587-594.

Listrat A., Bénédicte L., Louveau I., A struc T., Bonnet M., Lefaucheur L., P i c a r d B., B u g e on J. (2016). How muscle structure and composition influence meat and flesh quality. Sci. World J., 14.

L o c k y e r S., S t a n n e r S. (2019). Prebiotics - an added benefit of some fibre types. Nutr. Bull., 44: 74-91.

Macfarlane S., Macfarlane G.T., Cummings J. (2006). Review article: Prebiotics in the gastrointestinal tract. Aliment. Pharmacol. Ther., 24: 701-714.

Maharajana A., Rufus Kitto M., Paruruckumania P.S., Ganapiriyaa V. (2016). Histopathology biomarker responses in Asian sea bass, Lates calcarifer (Bloch) exposed to copper. JOBAZ, 77: 21-30.

Mansour M.R., Akrami R., Ghobadi S.H.,Amani Denji K., Ezatrahimi N., Ghara e i A. (2012). Effect of dietary mannan oligosaccharide (MOS) on growth performance, survival, body composition, and some hematological parameters in giant sturgeon juvenile (Huso huso Linnaeus, 1754). Fish Physiol. Biochem., 38: 829-835.

Maraschiello C., Diaz I., Garcia Regueiro J.A. (1996). Determination of cholesterol in fat and muscle of pig by HPLC and capillary gas chromatography with solvent venting injection. J. High Resolut. Chromatogr., 19: 165-168.

Markow i a k P., Śl i ż ew sk a K. (2018). The role of probiotics, prebiotics and synbiotics in animal nutrition. Gut Pathog., 10: 21.

Mazurki ewicz J., Przybył A., Golski J. (2008). Usability of fermacto prebiotic in feeds for common carp (Cyprinus carpio L.) fry. Nauka Przyr. Technol., 2: 3.

M i y a t a k e H. (1997). Carp (in Japanese). Yoshoku, 34: 108-111.

Moreira A.B., Vis entainer J.V., De Souza N.E., Matsushita M. (2001). Fatty acids profile and cholesterol contents of three Brazilian Brycon freshwater fishes. J. Food Compost. Anal., 14: 565-574.

Mousavi E., Mohammadiazarm H., Mousavi S.M., Ghatrami E.R. (2016). Effects of inulin, savory and onion powders in diet of juveniles carp Cyprinus carpio (Linnaeus 1758) on gut microflora, immune response and blood biochemical parameters. TrJFAS, 16: 831-838.

Munir M.B., H a s h i m R., M a n a f M.S.A., N or S.A.M. (2016). Dietary prebiotics and probiotics influence the growth performance, feed utilization, and body indices of snakehead (Channa striata) fingerlings. Trop. Life Sci. Res., 27: 111-125.

NRC (2011). Nutrient Requirement of Fish and Shrimp. Animal Nutrition Series. The National Academies Press, Washington, DC.

P ic colo G., Centoducati G., Bovera F., Marrone R., Nizza A. (2013). Effects of mannan oligosaccharide and inulin on sharpsnout seabream (Diplodus puntazzo) in the context of partial fish meal substitution by soybean meal. Ital. J. Anim. Sci., 12: 133-138.

P i i r o n e n V., To i v o J., L a m p i A.M. (2002). New data for cholesterol contents in meat, fish, milk, eggs and their products consumed in Finland. J. Food Compost. Anal., 15: 705-713.

P okus a eva K., Fitzgerald G.F., S inderen D. (2011). Carbohydrate metabolism in Bifidobacteria. Genes Nutr., 6: 285.

Priester C., Lindsay C.M., Ste phen T.K., Wade O.W., R i chard M.D. (2011). Growth patterns and nuclear distribution in white muscle fibres from black sea bass, Centropristis striata: evidence for the influence of diffusion. J. Exp. Biol., 214: 1230-1239.

P u c h a ła R., P i l a r c z y k M. (2007). The influence of nutrition on the chemical composition of carp meat (in Polish). Inż. Rol., 5: 363-368. 
Rabah S. (2005). Light microscope study of Oncorhynchus kisutch muscle development. Egypt. J. Aquat. Res., 31: 1.

Schmidt E.B., Arnesen H., de Caterina R., Rasmussen L.H., Kristensen S.D. (2005). Marine n-3 polyunsaturated fatty acids and coronary heart disease: Part I. Background, epidemiology, animal data, effects on risk factors and safety. Thromb. Res., 115: 163-170.

Scholz-Ahrens K.E., A de P., Marten B., Weber P., Timm W., A $\varsigma i l$ Y., Gluer C.C., S chrezen meir J. (2007). Prebiotics, probiotics, and synbiotics affect mineral absorption, bone mineral content, and bone structure. J. Nutr., 137: 838S-846S.

S te ffen s W., Wirth M. (2005). Freshwater fish - an important source of n-3 polyunsaturated fatty acids: A review. Arch. Polish Fish, 13: 5-16.

$\mathrm{S}$ t e ffe $\mathrm{ns}$ W., W i $\mathrm{th}$ M. (2007). Influence of nutrition on the lipid quality of pond fish: common carp (Cyprinus carpio) and tench (Tinca tinca). Aquac. Int., 15: 313-319.

S u n W., Li X., X u H., Ch e n J., X u X., L en g X. (2017). Effects of dietary geniposide on growth, flesh quality, and lipid metabolism of grass carp, Ctenopharyngodon idella. J. World Aquac. Soc., 48: 927-937.

Tak e u chi T., S a t o h S., K ir o n V. (2002). Common carp, Cyprinus carpio. In: Nutrient requirements and feeding of finfish for aquaculture, C.D. Webster, C. Lim (eds). CABI Publishing, New York, 245-261.

Talpur A.D., Munir M.B., Mary A., Hash im R. (2014). Dietary probiotics and prebiotics improved food acceptability, growth performance, hematology and immunological parameters and disease resistance against Aeromonas hydrophila in snakehead (Channa striata) fingerlings. Aquaculture, 426: 14-20.

Tavani ello S., M a i or a no G., Sta d n i cka K., Muc ci R., B o gu c k a J., B ed narczyk M. (2018). Prebiotics offered to broiler chicken exert positive effect on meat quality traits irrespective of delivery route. Poultry Sci. J., 97: 2979-2987.

Topic Popovic N., Strunjak-Perovic I., Coz-Rakovac R., Barisic J., Jadan M., Persin Berakovic A., S a uerborn Klobucar R. (2012). Tricaine methane-sulfonate (MS-222) application in fish anaesthesia. J. Appl. Ichthyol., 28: 553-564.

Tzortzis G., G ou la s A.K., G i b s o n G.R. (2005). Synthesis of prebiotic galactooligosaccharides using whole cells of a novel strain, Bifidobacterium bifidum NCIMB 41171. Appl. Microbiol. Biotechnol., 68: 412-416.

U 1 b r i c h t T.L.V., S o u th g a t e D.A.T. (1991). Coronary heart disease: seven dietary factors. Lancet, 338: 985-992.

Velasco S., Ortiz L.T., Alzueta C., Rebole A., Trevino J., Rodriguez M.L. (2010). Effect of inulin supplementation and dietary fat source on performance, blood serum metabolites, liver lipids, abdominal fat deposition, and tissue fatty acid composition in broiler chickens. Poultry Sci. J., 89: 1651-1662.

Wang J., Zhang D., Sun Y., Wang S., Li P., Gatlin D.M., Zhang L. (2016 a). Effect of a dairy-yeast prebiotic (GroBiotic-A) on growth performance, body composition, antioxidant capacity and immune functions of juvenile starry flounder (Platichthys stellatus). Aquac. Res., 47: $398-408$.

Wang K., Wang E., Q in Z., Zhou Z., Geng Y., Chen D. (2016 b). Effects of dietary vitamin E deficiency on systematic pathological changes and oxidative stress in fish. Oncotarget, 20: 83869-83879.

Wang R-F., An X-P., Wang Y., Q i J.-W., Zhang J., Li u Y.-H., Weng M.-Q., Yang Y.-P., G a o A.-Q. (2020). Effects of polysaccharide from fermented wheat bran on growth performance, muscle composition, digestive enzyme activities and intestinal microbiota in juvenile common carp. Aquacult. Nutr., 26: 1-12.

We a the r ley A., Gill H. (1989). The role of muscle in determining growth and size in teleost fish. Experientia, 45: 875-878.

Zhu T., Corraze G., Plagnes-Juan E., Quillet E., Dupont-Nivet M., Skiba- Cas s S. (2018). Regulation of genes related to cholesterol metabolism in rainbow trout (Oncorhynchus mykiss) fed a plant-based diet. Am. J. Physiol. Regul. Integr. Comp. Physiol., 314: R58-R70.

Z i m m e r m a n A.M.A., L o w e ry M.S. (1999). Hyperplastic development and hypertrophic growth of muscle fibres in the white seabass (Atractoscion nobilis). J. Exp. Zool., 284: 299-308. 
Ziółkowska E., B ogucka J., Dankowiakowska A., Rawski M., Mazurkiewicz J., S t a nek M. (2020). Effects of a trans-galactooligosaccharide on biochemical blood parameters and intestine morphometric parameters of common carp (Cyprinus carpio L.). Animals, 10: 723.

Received: 4 II 2021

Accepted: 22 IV 2021 